\title{
Locomotor Analysis of Surface Propulsion by Three Species of Reduced-Limbed Fossorial Lizards (Lerista: Scincidae) From Western Australia
}

\author{
CARL GANS AND MARGARET FUSARI \\ Department of Biology, University of Michigan, Ann Arbor, Michigan 48109 \\ (C.G.), and Environmental Studies, University of California, Santa Cruz, \\ California 95064 (M.F.)
}

\begin{abstract}
The relatively large, but superficially similar, Lerista macropisthopus, $L$. connivens, and $L$. lineopunctulata differ in bodily elongation and limb reduction, inhabit sandy areas, and move under sand. Visual analysis and computer-generated excursion and curvature graphs show that each species moves differently on smooth and rough surfaces, on surfaces with and without nails, and in channels.

The reduced-limbed quadruped, Lerista macropisthopus walks frequently, using its four clawed limbs, whenever traction is available. Its undulating body curves uniformly but never generates slide-pushing curves. The biped $L$. connivens walks with its hindlimbs, although less frequently, and/or oscillates its tail in propelling its relatively stiff, short body. The biped L. lineopunctulata rarely uses its hindlimbs but always undulates body and tail. It can use single nails in cam-follower progression. $L$. macropisthopus and $L$. connivens walk well in channels with rough bottoms, but only $L$. lineopunctulata uses tunnel concertina to travel in channels with smooth bottoms.

Friction of body surfaces dragged and of those transmitting propulsive forces is critical to these lizards and explains the division of movement into slow and rapid progression rates. Animals that have clawed limbs, no matter how reduced, use them. Body and tail generally are used differently. The tail may be flipped anteriorly to facilitate concertina. In nail arrays, travel is by simple, never by lateral, undulation. Apparently distinct motor coordination patterns are associated with differences in morphology, habit, and habitat. (c) 1994 Wiley-Liss, Inc.
\end{abstract}

Australia is the home of a series of parallel radiations of skinks that show varied degrees of bodily elongation and reduction of girdles, limbs, and digits (Gans, '75; Greer, '87, '90, '91a; Storr et al., '81); these conditions are often associated with distinct opportunities for life in vegetation, litter, and soil. An example is the scincid genus Lerista. Of its 54 (Greer, '89) to 70 (Kendrick, '91) species, seven occur in the vicinity of Hamelin Station at Shark Bay, W.A., Australia; here they are separated by subtleties of diet, body size, and habit (Kendrick, '91; Greer, '91b). All three species upon which this study is based occur in and/or under litter, or in the sandy soils surrounding the local Acacia shrubs.

The patterns of limb reduction of lizards have traditionally been analyzed from the viewpoints of morphology and development (reviews in Gasc, '77a,b, '81; for Lerista see Greer, '87, '90, '91b). Alternative reports have suggested that the pattern of limb reduction reflects developmental rather than functional constraints (Raynaud, '72, '74, '76, '85). However, past analysis has shown that seemingly similar-appearing lizards of diverse lineages often use quite different patterns for propulsion (Gans and Gasc, '90; Gase and Gans, '90) and that members of diverse genera show behavioral (kinematic) differences (Mushinski and Gans, '92; Gans et al., '92). Different patterns of sensorimotor coordination, rather than the mechanical

Address reprint requests to Dr. Carl Gans, Department of Biology, University of Michigan, Ann Arbor, MI 4.8109. 
capacity to form curves, appear to be the key for intergroup differences in lizard locomotor performance (Gans and Greer, '82; Gans, '85).

Most Lerista are litter dwellers; many species live in loose sand. Several species of Lerista are sand swimmers (Greer, '91a; Storr et al., ' 81 ), and their specialization and partitioning of the habitat involve limb reduction and locomotor modifications. Kendrick ('91) noted that "sympatry is maintained among species with divergent morphologies and ecologies, whereas species with very similar morphologies occur as allopatric replacements." This suggests that sympatry may reflect differences in functional approaches to the substratum.

This paper is one of a series of analyses intended to characterize the locomotion of elongate ectotherms by testing their responses to specific tasks. It attempts to determine the extent to which the morphological variation associated with elongation and limb loss is reflected in the locomotor pattern and allows conclusions about evolutionary steps leading to the limbless condition. The present paper reports on locomotor differences among three sympatric, superficially similar species of a single genus showing a range of bodily elongation and limb reduction.

\section{MATERIALS AND METHODS}

Lizards were collected at Shark Bay, W.A. Australia, and exported under permit. Subsequently the animals were maintained in the Laboratory of Functional Ecology, at Cornell University, in groups of two to four in cages with $4 \mathrm{~cm}$ of sand. An incandescent lamp at one end of the cage created a photothermal gradient, while ultraviolet light (UVA) was provided by fluorescent lamps mounted 45 $\mathrm{cm}$ above the cages, both for $8 \mathrm{hr}$ a day. Lizards were fed a mixed diet of insect larvae dusted with powdered vitamins, calcium, and phosphorus (Theralin and D-CA Fos; see Pough, '91, for sources and details). The sand in one corner of the cage was kept wet. Boards provided hiding places. For this study, lizards were transported to the University of Michigan at Ann Arbor, housed similarly, and returned to Cornell 3 weeks later.

Long body measurements (e.g., snout-vent, intergirdle length) were taken by pressing the specimens against the edge of a box and reading directly from a $\mathrm{mm}$ rule. Head measurements, body widths, and limb lengths were taken, using a dissecting scope with an ocular micrometer. As broken caudal tips were a problem, and not always easy to distinguish, caudal length and proportion were compared from the five specimens having the longest tails for the species. Very few specimens of Lerista macropisthopus had tails without some distal loss. Measurements were adjusted, using the appropriate regression of log measure on log snout-vent length, to the dimension the measurement would have been if each lizard had a snout-vent length of 77.3 $\mathrm{mm}$, the grand mean value. Significance was determined using a one-way analysis of variance (ANOVA) (Excel 4.0). Vertebral numbers derive from the studies of Greer ('87, '91a,b).

The lizards were videotaped at the University of Michigan at Ann Arbor as they traversed four different substrates at temperatures between $25^{\circ}$ and $30^{\circ} \mathrm{C}$. A $10 \times 10-\mathrm{cm}$ grid of black threads suspended just above the surfaces (but out of contact) provided a spatial reference for analysis. The animals were encouraged to move by touching them with a soft brush or vibrating the substrate. Lizards were videotaped from an angle near $60^{\circ}$ at $30 \mathrm{fps}$ using a SONY CCD-F56 Handycam. The 8-mm tape was then converted to VHS format, sometimes using a contrast enhancing circuit. Tapes were analyzed with a Panasonic AG-6300 Omnivision II projector. Selected images for locomotion on flat surfaces were digitized using a proprietary ATcomputer-based shape-digitizing analytical system that corrects for camera angle and permits determination of center of gravity, curvature, and similar aspects from each of a sequence of images. Only sequences of at least three continuous cycles in a straight line were digitized. The sequences thus analyzed were compared visually with shorter ones and with those in which the lizards had turned.

The first test used two flat surfaces, a smoothly varnished plywood, and a plywood transformed into sandpaper by the application of sand on dilute white glue. The second test consisted of fields of 2 -inch nails, placed at $2.0 \times 2.0,4.0 \times 4.0$, and $8.0 \times 8.0-\mathrm{cm}$ grid spacings, respectively, on smooth surfaces and sandpaper. The third test consisted of $1.0,2.0$, and $4.0-\mathrm{cm}$-wide (5-cm-deep) Plexiglas channels; plain (PG), with $3 \mathrm{M} 100 \mathrm{Me}-$ dium SO 32 open-coat sandpaper only on their walls (SPW), and with sandpaper only on their floors (SPF). A fourth test involved placing lizards on top of, or next to, a shallow (1- to 2-cm) layer of sand and observing their 
reactions. A total of $2 \frac{1}{2} \mathrm{hr}$ of tape was analyzed $(45 \mathrm{~min}$ on flat surfaces, $25 \mathrm{~min}$ in fields of nails, $20 \mathrm{~min}$ in channels, and an additional $60 \mathrm{~min}$ on shallow sand).

The animals were placed onto the various surfaces, near one end of the available area, but far enough into it so that a substantial distance separated them from the edge and did not lead to reversal and possible escape. Placement into channels was always with about one body length of free space beyond the tail. Placement was always gentle, and the animal was allowed to rest for about 1 min, before being touched with a camel'shair brush. For flat surfaces we tested five Lerista lineopunctulata (4 were digitized for computer analysis), four $L$. connivens ( 3 digitized), and five L. macropisthopus (3 digitized) (one with tail autotomized to its base and regrown). In channels and on surfaces with nails, we used one of each species; on sand we used five $L$. lineopunctulata, three $L$. connivens and five L. macropisthopus (including the one with the autotomized and regrown tail).

Velocities for lizards traveling on flat surfaces were calculated from coordinates taken from the digitized images for head and center of mass. Velocities in channels were determined from video records for travel by timing each traverse of $10 \mathrm{~cm}$ and converting to $\mathrm{cm} / \mathrm{sec}$. Statistical analysis of the former was by paired $t$-test (Excel, 4.0) for travel on smooth and rough surfaces. The sample sizes for channel travel were too small for statistical analysis. Velocities were not adjusted for differences in body length.

The locomotor methods described as used by Lerista are walking (using the limbs), simple undulation (not the more advanced lateral undulation, which involves a complex sensorimotor coordination of the body at multiple local points of contact with the lateral surfaces, as seen in snakes; Gans, ' 85 ), simple concertina, limbed concertina, and slide pushing used as previously defined (Gans, '86). Simple undulation involves the formation of sinusoidal curves and their posterior passage along the trunk invoking resistance posterolateral to the body. Concertina locomotion involves static fixation of the force transmitting portions of the trunk or limbs and the alternating progression of the anterior and the posterior portions of the body (thus bending its center). Forces are transmitted by muscular expansion of body waves against the walls of a tunnel (tunnel or channel con- certina), or by the alternating placement of front and of hindlegs (limbed concertina). Slide-pushing involves propulsion by sliding contact of ventral zones of the body against a flat (horizontal) surface.

\section{Species studied}

The present locomotor analyses were carried out on six adult individuals each of the species Lerista lineopunctulata, L. connivens, and L. macropisthopus. Only some individuals were used in each test. The three species are widely sympatric at Shark Bay, although the predominance of individual species at particular sites correlates with soil and litter type (Kendrick, '91, unpublished observations).

Lerista lineopunctulata is a member of the L. nichollsi group (Kendrick, '91). It is highly arenicolous, inhabiting loose, relatively deep sands along the Western Australian coast (Kendrick, '91). Individuals dive rapidly into these sands upon disturbance.

Lerista connivens is another member of the $L$. nichollsi group, closely related to $L$. lineopunctulata (Kendrick, '91), although Storr et al. ('81) treat $L$. lineopunctulata as a member of the separate "bipes" group. At Shark Bay, it inhabits loose and shallow (2to $6-\mathrm{cm}$ ) reddish sands that overlie a clay hardpan (Kendrick, '91). It enters sand quickly whenever disturbed.

Lerista macropisthopus, a member of the L. macropisthopus group, is distantly related to the other two species. It often occurs on hard soils, such as clay pans or dense shell soils (Kendrick, '91). Most of our specimens came from a cockleshell substrate, hardpacked but not consolidated, which would not permit sand swimming, although this lizard does sand-swim well, once immersed in loose sands.

\section{RESULTS \\ Morphology}

All three species of Lerista show morphologies derived over the ancestral skink pattern in having elongate bodies with an elevated number of presacral vertebrae, small heads with wedge-shaped snouts and countersunk mandibles, and reduced numbers of digits and phalanges. The body has shallow depressions into which the adpressed limbs fit. These correlate with fossorial habits in many squamate lineages. However, the reduction pattern of the limbs does not represent a 
single linear sequence (Greer, ' 87 ). The heads are narrower than the trunk, and differ only slightly among the three species, with the dorsal surface always curving down to a rostral point, and narrowing to a snout that is approximately one-third the width of the temporal region.

Our three species of Lerista differ in limb pattern and vertebral numbers and in body proportions (Table 1, Fig. 1). The massive $L$. lineopunctulata is the largest of the three species studied. Our six specimens average $111.7 \pm 3.8 \mathrm{~cm}$ snout-vent length and weigh $11.0 \pm 0.6 \mathrm{~g}$ (mean \pm 1 standard error, $\mathrm{SE}$ ). Over most of the range, specimens of $L$. lineopunctulata lack forelimbs, although those from the Perth area (Bold Park) have small, unclawed nubs in the pectoral region. $L$. lineopunctulata has the greatest $\operatorname{limb}$ reduction (1-2 relatively small hind toes), and more presacral vertebrae (46-48) than that of the other species. Their trunks are relatively narrow, much more than those of the other two species, especially immediately anterior to the pelvis. The heavy and muscular tails have 41-42 postsacral vertebrae.

Lerista connivens has the fewest presacral (41-43) and postsacral (38) vertebrae of the three species studied. Our six specimens average $79.2 \pm 2.7 \mathrm{~cm}$ snout-vent length and weigh $6.3 \pm 0.5 \mathrm{~g}$ (mean $\pm 1 \mathrm{SE}$ ). The intergirdle length is significantly shorter, the trunk significantly wider and the tail significantly shorter than in the other two species. L. connivens lacks forelimbs and has twotoed hindlimbs. The trunks are stiff in the intergirdle zone and narrowest just behind the head. The tails are stout, bend near their base, and taper distally to sharp points.

Lerista macropisthopus is relatively long with it's trunk narrowest just posterior to the head. Our six specimens average $7.2 \pm$ $3.5 \mathrm{~cm}$ snout-vent length and weigh $6.2 \pm 0.6$ $\mathrm{g}$ (mean $\pm 1 \mathrm{SE})$. Their long and flexible tails taper only at the tips and have more postsacral vertebrae (48) than those of the other two species. There are 43-46 presacral vertebrae. The intergirdle zones are attenuate and flexible and the pelvic zones well defined. $L$. macropisthopus has slight forelimbs with two toes and relatively substantial hindlimbs with three toes each.

The vertebral numbers differ only slightly among the three species; calculation of mean presacral number per mean SVL (snout-vent length) of the specimens used by us yields lower values for Lerista lineopunctulata $(0.42$ vertebrae per unit of SVL) than for L. connivens ( 0.53 vertebrae per unit of adult SVL) and $L$. macropisthopus (0.56 vertebrae per unit of SVL). However, our specimens of $L$. lineopunctulata were unusually long. L. macropisthopus has more presacral vertebrae, relative to the degree of limb reduction, than predicted from the graphs of Greer ('87, '90) (observed mean $=44.5$, predicted $=39.9$ ). By contrast, L. lineopunctulata has 47 (predicted $=46.5$ ) and $L$. connivens has 42 (predicted $=43.3$ ), both much closer to the predicted values. These values suggest that the relationship between adult SVL and number of presacral vertebrae are not directly correlated.

Toe numbers do not correlate directly with limb proportions. The hindlimbs of Lerista lineopunctulata, which have one (occasionally two) toes per hindlimb, are significantly shorter than those of $L$. connivens and $L$. macropisthopus. L. connivens and L. macropisthopus have hindlimbs of approximately equal lengths, although $L$. connivens has two hindtoes, whereas $L$. macropisthopus has three. Whatever the phalangeal number, all phalanges bear claws (except for the small nubs in the pectoral region of $L$. lineopunctulata from the Perth area).

These three species fall among the larger Lerista, size being a characteristic associated

TABLE 1. Adjusted body dimensions for a sample of preserved specimens of the three species of Lerista ${ }^{1}$

\begin{tabular}{|c|c|c|c|c|c|}
\hline Width 1 & Width 2 & Width 3 & IGL & Tail & HTOE \\
\hline \multicolumn{6}{|c|}{ L. lineopunctulata } \\
\hline $6.5 \pm 0.3$ & $6.5 \pm 0.3$ & $5.9 \pm 0.3^{*}$ & $57.1 \pm 0.5$ & $70.1 \pm 0.6$ & $7.2 \pm 0.8^{*}$ \\
\hline \multicolumn{6}{|c|}{ L. connivens } \\
\hline $7.1 \pm 0.3^{*}$ & $8.1 \pm 0.2^{*}$ & $7.8 \pm 0.2$ & $55.1 \pm 0.9^{*}$ & $60.4 \pm 2.8^{*}$ & $13.3 \pm 0.6$ \\
\hline \multicolumn{6}{|c|}{ L. macropisthopus } \\
\hline $6.6 \pm 0.2$ & $7.0 \pm 0.4$ & $7.2 \pm 0.4$ & $56.7 \pm 0.8$ & $67.1 \pm 5.2$ & $12.8 \pm 0.8$ \\
\hline
\end{tabular}

${ }^{1}$ Metrics $(\mathrm{mm})$, adjusted for the grand mean snout-vent length of $77.3 \mathrm{~mm} \pm \mathrm{SE}$. Significant differences among species are indicated by asterisk $\left(^{*}\right)$ within each column at $P \leq 0.05$. (These were not the lizards used in the locomotor trials.) Abbreviations: HTOE, length of hindtoe; WIDTH1, body width 10 scale rows behind head; WIDTH2, width at midbody; WIDTH3, width immediately anterior to pelvis; IGL, intergirdle length; TAIL, length of tail. 

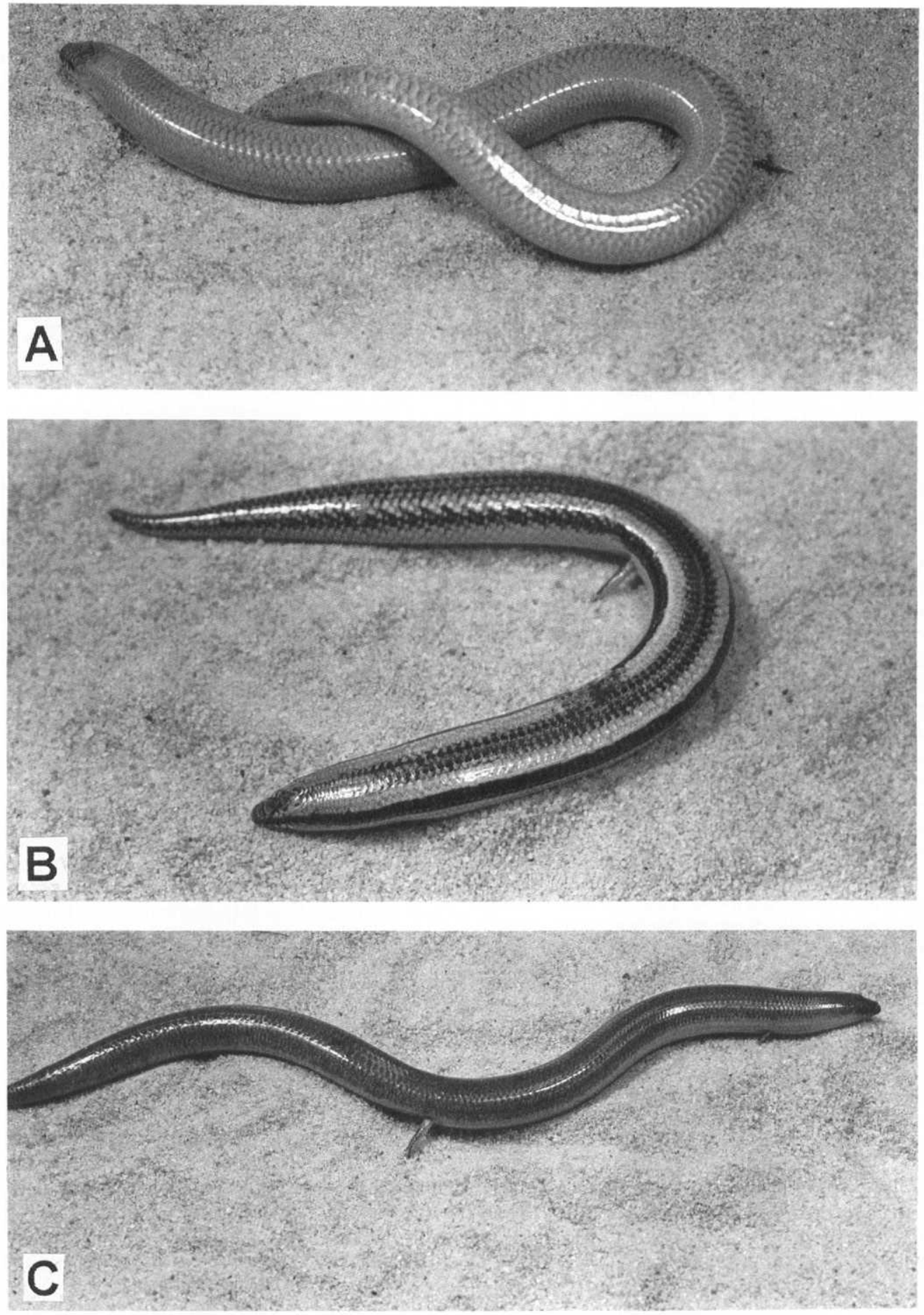

Fig. 1. Lerista. Specimens from Shark Bay, Western Australia, of the three species studied showing the typical resting position of the trunk. A: L. lineopunctulata. B: $L$. connivens. C: $L$. macropisthopus. Intergirdle lengths are roughly equivalent ( $\sim 55 \sim 57 \mathrm{~mm}$; see Table 1$)$. 
with fossoriality in the genus (F.H. Pough, personal communication).

\section{Motor patterns \\ Flat surfaces: kinematics}

Whenever initially placed on a flat surface, the animals differ in the number of curves each forms along the trunk (Fig. 1). For Lerista lineopunctulata the trunk comprises up to a single full $S$ curve, generally of an amplitude of one-half the wavelength. Often the tail is brought anteriorly to curve around the trunk. By contrast, trunk and tail of $L$. connivens form a single $\mathrm{C}$ shape, or a shallow $\mathrm{S}$ curve. The trunk of $L$. macropisthopus appears more flexible and generates up to $1 \frac{1}{2}$ $S$ curves, often irregular and of variable depth. The head of $L$. lineopunctulata tends to point in the direction along which the animal will travel; however, the heads of the other two species continue the orientation of the neck, regardless of the direction of progression. Also, disturbed $L$. lineopunctulata will depress the tip of the snout against the surface, arching the neck off the ground, whereas the heads and trunks of the other forms remain parallel to and in contact with the surface.

All three species traverse flat surfaces by a combination of walking, limbed concertina and slide pushing. In walking, the anterior body may be kept straight and the tail dragged, or foot placement may be enhanced by lateral bending of the trunk; the animals often travel slowly and intermittently. In limbed concertina, the initially curved anterior end of the body straightens, accelerating the anterior end forward. The walking (hind) limbs seemingly attempt to transmit forces to the substrate, with success differing according to species and texture of the surface. In slide pushing, the posterior portion of trunk and tail is swung in a curve, pushing over the surface, resulting in forward acceleration of the center of gravity (or of the anterior body).

On flat surfaces, fresh animals move continuously or intermittently. They form lowamplitude, posteriorly traveling waves along the trunk, all portions of which proceed at approximately equal rates along the path traced by the center of gravity. Each hindlimb tends to stride as the concave portion of the wave approaches the girdle on its side and to push posteriorly as the bend passes the girdle. This curve-stride synchrony breaks down whenever the claws slip on the smooth surface. One then sees cycling of multiple and rapid "strides" without obvious propul- sive effects. On rougher surfaces (sandpaper), the claws of the hindlimbs tend to make good contact, and one can see the effect of local acceleration with each successful stride. Lerista lineopunctulata, and to a much lesser extent $L$. connivens, practice pure slide pushing, with the backward passing contact sites accumulating propulsive resistance; in contrast, L. macropisthopus does not show the wide swings of the trunk or tail and uses its limbs in limbed concertina. L. lineopunctulata and especially $L$. connivens will occasionally use the limbs, especially on rougher surfaces. $L$. connivens shows a combination of slide pushing and walking.

Figure 2 displays these differences in pattern for representative individuals that are traversing a rough, flat surface. Lerista lineopunctulata, progressing primarily by slide pushing, moves much more slowly with much greater curving of the body and lateral and anterior displacement of the tail than is seen in the other two species. By contrast, L. macropisthopus progresses more swiftly, primarily by walking, and shows very little bending. The pattern displayed by $L$. connivens is similar to that of L. lineopunctulata in that both use the tail in slide pushing, but similar to $L$. macropisthopus in walking stride, in that both use the limbs with little lateral displacement of the trunk.

Whenever the locomotor patterns become more irregular, possibly because the lizards become fatigued, the propulsive waves alternate between front and rear, curving and then extending the trunk. This generates a kind of concertina locomotion along the path of the center of gravity. Consequently, each point on the body and limbs accelerates and decelerates in both parallel and perpendicular directions relative to the axis of the $S$ curves. For Lerista lineopunctulata, the intermittent acceleration of the pelvic relative to the pectoral girdle generates a shallow extra loop between the girdles; next the pectoral zone is accelerated, straightening this curve. For $L$. macropisthopus, the acceleration of the pelvic girdle generates one or more major curves even farther anteriorly. This allows intermittent acceleration of the pectoral zone so that propulsion is by a concertina pattern, both on smooth surfaces and on the surface of loose sands. The progression may slow, but does not always come to a full stop. By contrast, $L$. connivens, which has less axial flexibility and the shortest relative inter- 

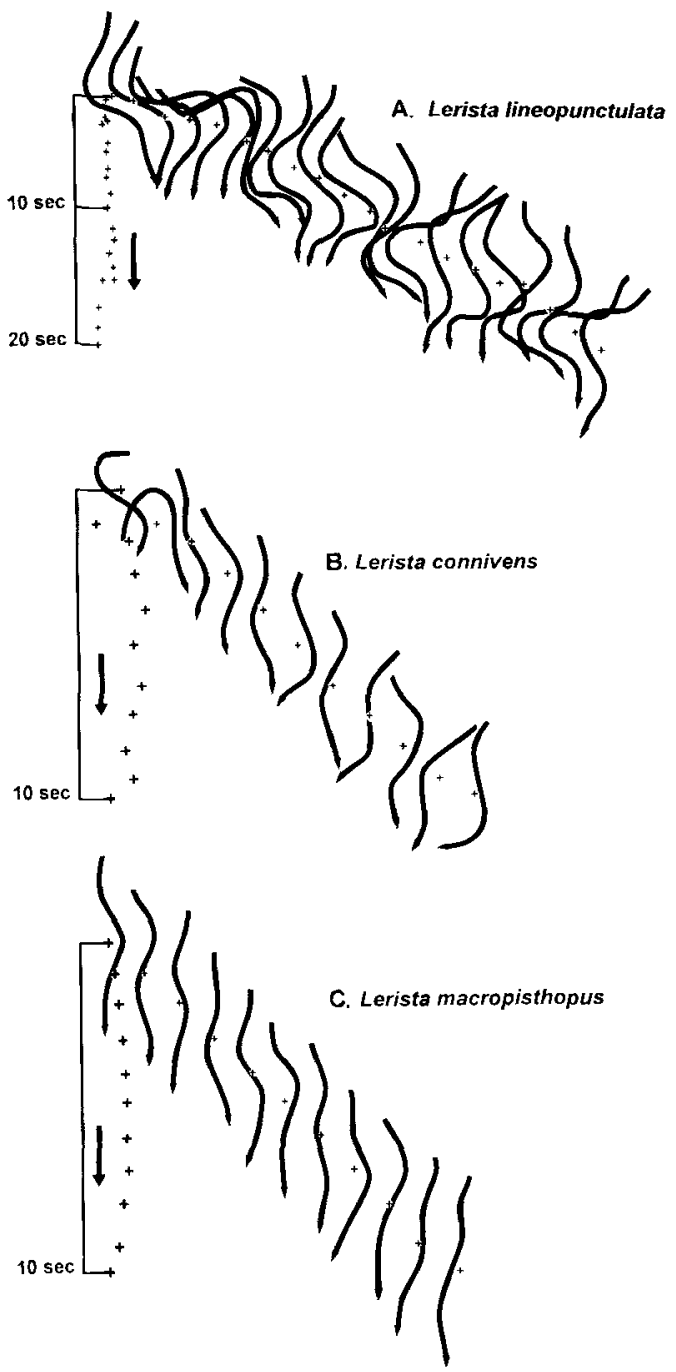

Fig. 2. Lerista. Representative sequences of lizards, locomoting on a flat surface, traced from plots of video images with each progressive image displaced to the right. Crosses indicate center of gravity, rows of crosses on left margin indicate actual path of travel. Arrow, Direction of travel. Vertical bar, time elapsed. A: $L$. lineopunctulata. B: L. connivens. C: L. macropisthopus.

girdle length, continues to propel itself by slide pushing rather than concertina.

Velocities of travel over plain (smooth) surfaces are similar for Lerista macropisthopus and $L$. connivens (Table 2 ). $L$. lineopunctulata moves more slowly. As $L$. lineopunctulata is approximately $135 \%$ longer (snoutvent length) than the other two species (which are approximately equal in snout-vent
$T A B L E 2$. Velocities of the centers of gravity of three species of Lerista in travel over smooth and roughened surfaces ${ }^{1}$

\begin{tabular}{lccc}
\hline Species & Smooth & $P$ & Rough \\
\hline L. lineopunctulata (3) & $0.68 \pm 0.07$ & 0.01 & $1.09 \pm 0.03$ \\
L. connivens (4) & $2.74 \pm 0.13$ & 0.18 & $2.40 \pm 0.38$ \\
L. macropisthopus (2) & $2.23 \pm 0.52$ & 0.08 & $3.12 \pm 0.30$
\end{tabular}

${ }^{1}$ Numbers in parentheses are sample sizes. Values are cp $\pm \mathrm{SE} . P$ values, for paired $t$-tests, are for smooth versus rough surfaces within species. (Lizards are of different lengths.)

length), scaling the travel to body lengths per second would make the difference even more apparent.

Lerista lineopunctulata travels significantly faster on rough surfaces than on smooth surfaces (significance for head, $P \leq 0.04$; and for center of gravity, $P \leq 0.01$ ). L. macropisthopus travels significantly faster on rough surfaces according to head velocities $(P \leq 0.02)$ (velocity of center of gravity differs only at $P \leq 0.08$ ). There is no significant difference in either head or center of gravity velocity for L. connivens on the two surfaces. Also, the velocities of the heads and centers of gravity do not differ significantly between any sequences.

Whenever individuals enter loose sand from the top surface or from the side of a pile, they show differences in propulsion. Lerista macropisthopus usually walks across the top surface for one to two body lengths before attempting to burrow, whereas $L$. connivens and L. lineopunctulata burrow immediately. Both $L$. macropisthopus and $L$. connivens penetrate the sand using forces generated by the hindlimbs, whereas $L$. lineopunctulata enters the sand using widely oscillating slide pushing of the posterior body.

\section{Flat surfaces with nails: kinematics}

During travel through fields of fixed nails, the animals continue the locomotor patterns seen on flat surfaces, both smooth and rough. In all of the species, the waves passing down the trunk are established internally with minimal response to environmental cues. Lerista lineopunctulata and especially L. connivens tend to keep the body tonically stiffened in such arrays (one can slide them over the surface without the curve pattern being deformed); this is less obvious in L. macropisthopus. During passage of widely spaced nails, contact by a posteriorly traveling wave of the trunk with a nail produces a reaction force that may deflect the position of the entire animal, but need not affect the shape of the 
curves passing down the trunk. On travel over smooth surfaces, the curvatures always move rapidly down the trunk.

Whenever the vector of the initial reaction force is normal to the surface of the animal, the direction of the animal's displacement is maintained. However, contact at another angle will produce slippage along the interface and one can see irregular (jerky) movement of the animal. If the movement of the wave is at an angle to the path of the center of gravity, contact induces slippage toward the obtuse side of that angle. The magnitude of slippage will always be greatest whenever the coefficient of surface friction is low; it is minimal whenever traversing sandpaper. Whenever encountering lateral resistance sites, the limbs fold into the depressions in the body wall.

Traverse of surfaces with an internail spacing approaching and being less than the amplitude of trunk curvature increases the probability that the curves of the traveling animal will encounter multiple sites simultaneously. This makes it likely that slippages and reaction forces will be in opposite directions and will cancel each other in whole or in part. Propulsion in more narrow arrays then involves a more effective transmission of directed forces and traveling bends are likely to maintain contact with particular resistance sites (because excursion is limited by other sites). Travel need not be fast and continuous, but it may well be less regular, and is often slow.

The locomotor patterns continue the trend toward a directed path as the nail spacing becomes very narrow. The head and trunk can then be slid forward by posteriorly applied forces; their intrinsic stiffness will let them be moved in a more or less straight line along an alley formed by nails, as long as the axis of the head and neck contacts the wall of the alley at an acute angle. However, a sharper turn at the neck may cause the head to be slipped between two of the bordering nails, redirecting the path of the animal. Consequently, travel through a tightly spaced array of resistance sites restrains the amplitude of the intrinsic curvature of the trunk; the path then becomes modified by the position of the head and neck. The distance over which such a straight-line push will be successful falls as the frictional resistance of the surface increases, whereas the effectiveness of the feet is increased by the greater friction.

\section{Flat surfaces: excursion graphs}

In an undulating lizard, each point along the trunk travels a path with a lateral excursion greater than that of the animal as a whole, i.e., greater than the excursion of its center of gravity. The graphs of excursion (of points from head to tail, relative to that of the center of gravity) (Fig. 3) characterize the interspecific and inter-substrate differences. Peaks on the excursion graphs indicate exceptional lateral displacement of specific points along the animal.

Mean excursion graphs for Lerista $l i$ neopunctulata (Fig. 3A,B) show lateral displacement of the head to be the most extreme of the three species (130-170\% of the center of gravity), especially on rough surfaces. The graph for the trunk shows a deep S shape with a minimum (of 110-130\%) in the anterior half and a maximum (of $155-180 \%$ ) in the posterior half. A second minimum (of $135-140 \%$ ) occurs, usually posterior to the cloaca after which the excursion rises smoothly toward the caudal tip; this maximal excursion of any of the three species (of 220$290 \%$ ) documents wide lateral oscillations of the tail, indicative of the use of slide pushing in locomotion.

For Lerista connivens, the mean excursion graphs (Fig. 3C,D) show moderate lateral displacement of the head (105-125\%). There are relatively shallow maxima on the posterior half of the trunk (90-120\% on smooth and 95-120\% on rough surfaces). The trunk sometimes shows a displacement less than that of the center of gravity. There is no inflection of the curve at the cloaca although the presacral and caudal amplitudes may differ. The caudal displacement begins with low excursions $(95-120 \%)$ that rise (to 130 $190 \%$ ) at the caudal tip, again indicating strong oscillation of the tail due to slide pushing locomotion. The path of the trunk and the anterior portion of the tail shows less displacement on rough than on smooth surfaces.

The heads of Lerista macropisthopus have less lateral displacement than those of the other two species (105-110\%) (Fig. 3E,F). In contrast to the trunk of $L$. connivens, the excursions of the trunk of $L$. macropisthopus always are greater than those of its center of gravity. There is low maximal displacement in the posterior half of the trunk (115$120 \%$ ), especially on the rough surface. The tail shows low peaks (110\%), and the displacement only rises to $105-130 \%$ at the tip. For 


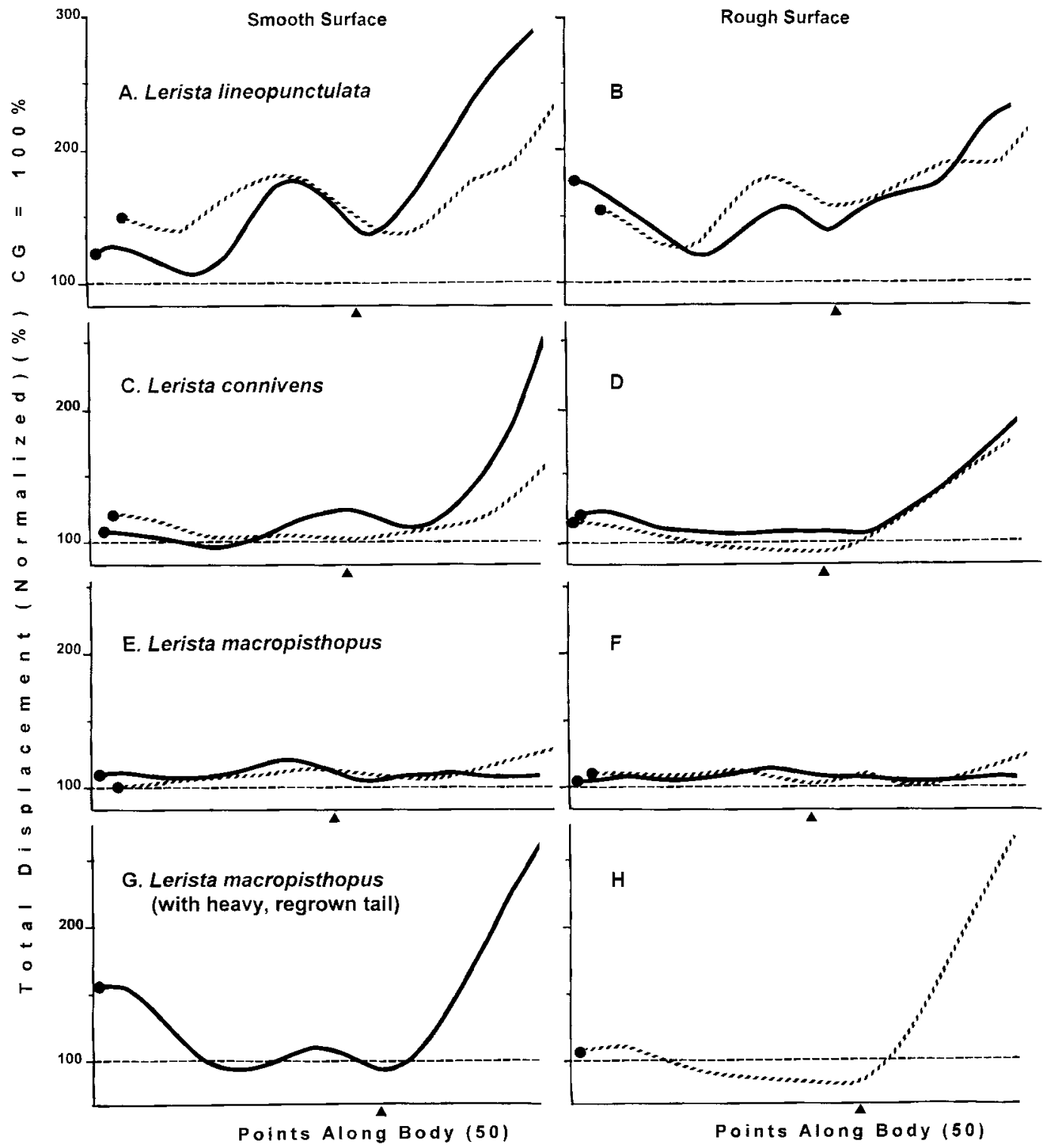

Fig. 3. Lerista. Displacement graphs for locomoting lizards showing lateral excursion relative to the path of the center of gravity along the body. Dark circles indicate heads, triangles position of cloacae. Locomotion patterns for seven individuals are illustrated. Each curved line indicates an individual lizard on a smooth (A,C,E,G) or a rough surface $(\mathbf{B}, \mathrm{D}, \mathrm{F}, \mathrm{H})$. A,B: $L$. lineopunctulata $(\mathbf{N}=2)$. C,D: L. connivens $(\mathbf{N}=2)$. E,F: L. macropisthopus normal tail $(\mathbf{N}=2)$. G,H: L. macropisthopus heavy, regenerated tail $(\mathbf{N}=1)$.

the most part, this species is walking rather than slide pushing.

Excursion graphs of a single individual of Lerista macropisthopus with a completely autotomized and heavy, regenerated tail (Fig. $3 \mathrm{G}, \mathrm{H})$ show a very different pattern from those for the norm for the species. On a smooth surface, the head displaces more (155\%) and the trunk shows variable displacement $(80-110 \%)$. On the rough surface, the head displaces little (115\%), and the trunk displaces to only $80 \%$ of displacement ampli- 
tude of the center of gravity. For both surfaces, the excursion posterior to the cloaca increases smoothly to $260 \%$, indicating wide swings of the tail although there are no bends of the tail and hence no slide pushing. The excursion graph of this specimen is closer to that of $L$. connivens than to that of an undamaged L. macropisthopus.

\section{Flat surfaces: curvature graphs}

The curvatures of the animals differ locally from neck to tail. The graphs, plotted as the reciprocal of the radius of curvature $\left(\mathrm{cm}^{-1}\right)$ show mean and maximum curvature averaged over a series of locomotor cycles. They further characterize interspecific and intersubstrate differences (Fig. 4). The peaks and valleys on the mean curvature graphs identify positions on the body at which the animal bends most and least sharply. Peaks on the graphs for excursion maxima correspond to specific points of exceptional curvature along the animal. The differences between the distributions of mean and maximum curvatures reflect the variability of curvature along the trunk.

For Lerista lineopunctulata traversing smooth and rough surfaces, the curvature graphs show mean magnitudes from 0.2 to $0.4 \mathrm{~cm}^{-1}$ (Fig. 4A-D). The mean curvature shows variable peaks and there is no obvious trend in terms of an anterior or posterior zone having the greatest magnitude. The maxima average about two to four times the mean curvatures, greater curvatures are uncommon. The position of the cloaca is not defined by particular changes of curvature on smooth surfaces. On rough surfaces, only one specimen has the position of the cloaca defined by a clear curvature minimum.

On smooth surfaces, Lerista connivens shows a mean curvature of $0.1-0.4 \mathrm{~cm}^{-1}$ (Fig. 4E,G). One record shows a rounded peak in the mean curvature $\left(0.35 \mathrm{~cm}^{-1}\right)$ posterior to the cloaca and another one shows such a peak further on the tail. The maximum values average about twice the mean curvature but peaks three times the mean may occur on the trunk, and again on the tail. On rough surfaces, the maximum curves show one to two peaks on the trunk and an equal number on the tail, although in one specimen the caudal maxima appear fused into a high plateau (Fig. 4F,H). The position of the cloaca is clearly marked by a minimum of the mean on a single record from the rough surface.
The mean curvature for Lerista macropisthopus moving on smooth surfaces is $0.1-0.3$ $\mathrm{cm}^{-1}$ (Fig. 4I,K) for the one to two curves on the trunk. The values of maximum curvature are two to $2 \frac{1}{2}$ times the amplitude of the mean. The cloaca is well indicated with minima in both mean and maximum curves at or immediately posterior to it. On rough surfaces, the mean curves average 0.1-0.35 $\mathrm{cm}^{-1}$ (Fig. 4J,L). The maximum parallels the mean curvature, being twice as large. However, two to three larger, narrow peaks appear. The cloaca is well marked, in that peak values appear coincidentally just anterior and posterior to it. The caudal region then shows a gradual decrease of both curves toward the caudal tip with the maximum curvature representing one to two shallow peaks.

The single specimen of Lerista macropisthopus with a completely autotomized and regenerated tail shows mean curvatures of $0.15-0.4 \mathrm{~cm}^{-1}$ along the trunk on smooth and $0.15-0.3 \mathrm{~cm}^{-1}$ on rough surfaces. For the smooth surfaces, the maximum values roughly parallel the means; each shows two peaks on the trunk and two smaller peaks on the tail. For the rough surfaces, the maximum curve lacks extreme peaks on the trunk. For smooth surfaces, the precloacal peak in the mean curve extends onto the anterior portion of the tail, whereas in the maximum curve the precloacal peak terminates at the cloaca. For rough surfaces, neither the mean nor the maximum curves show inflections defining the position of the cloaca.

The sequences hence show much variability. Whereas minor trends appear, such as the definition of the cloacal zone in Lerista macropisthopus, the mean values are otherwise equivalent. Furthermore, the maximum values for any sequence may occur anywhere along the animal. This documents local flexibility and is in contrast with the following observations.

\section{Channels}

The channels impose the task of travel along a path defined by parallel sides. Combinations of three path widths and two frictional coefficients of bottom and sides are available. The velocities and movement patterns along a channel of the three species of Lerista differ. In 1-cm channels, progression appears to be difficult as indicated by highly irregular movements by all three species. In 2 -cm channels, the pattern of each species is distinct. 

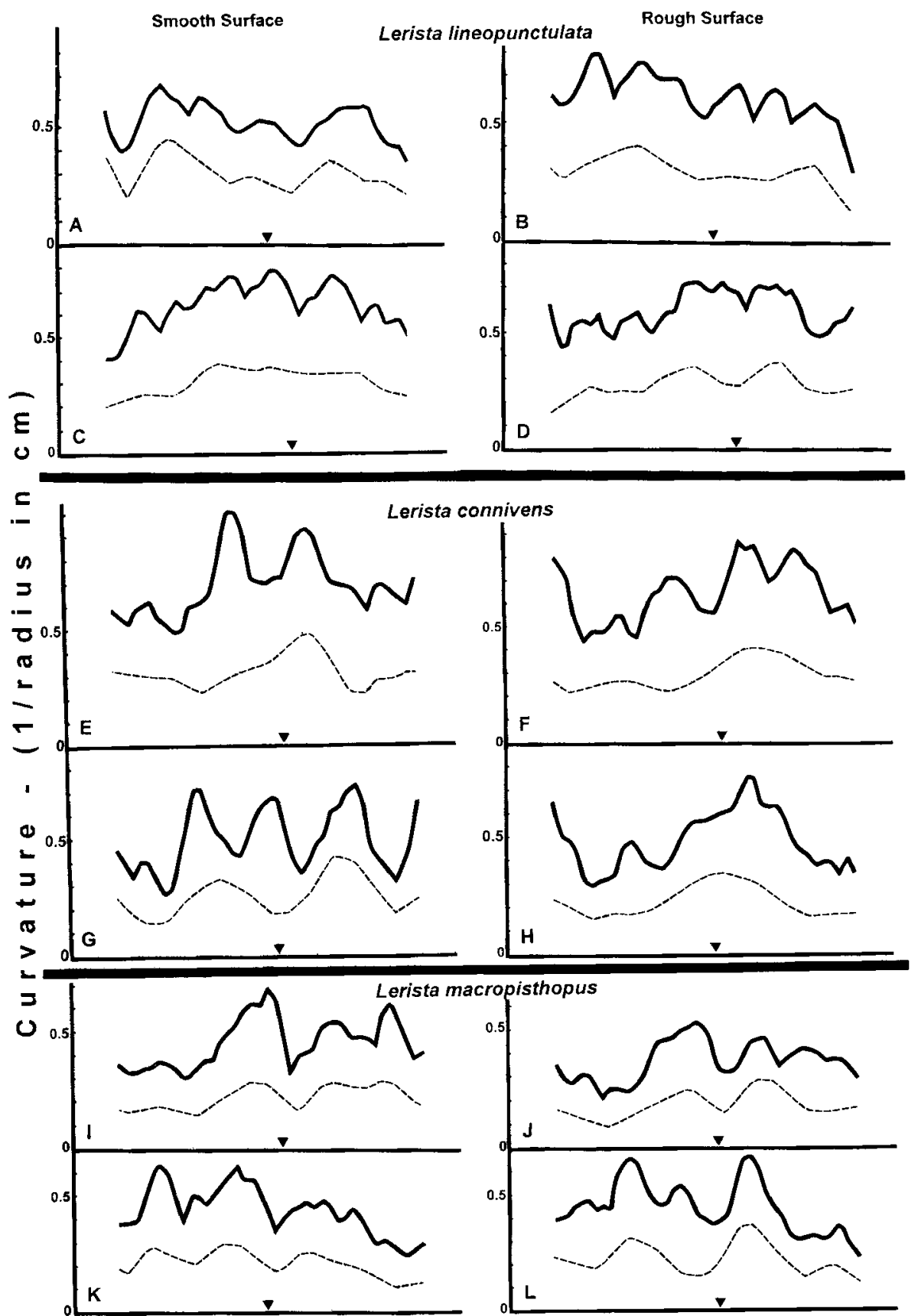

Points Along Body (50)

Fig. 4. Lerista. Curvature graphs for locomoting lizards showing maximum (solid line) and average (dashed line) curvature along the body. Heads are to the left. Cloacae are indicated by triangles. Of 50 points analyzed for each animal, points 6-45 are plotted. Six individuals
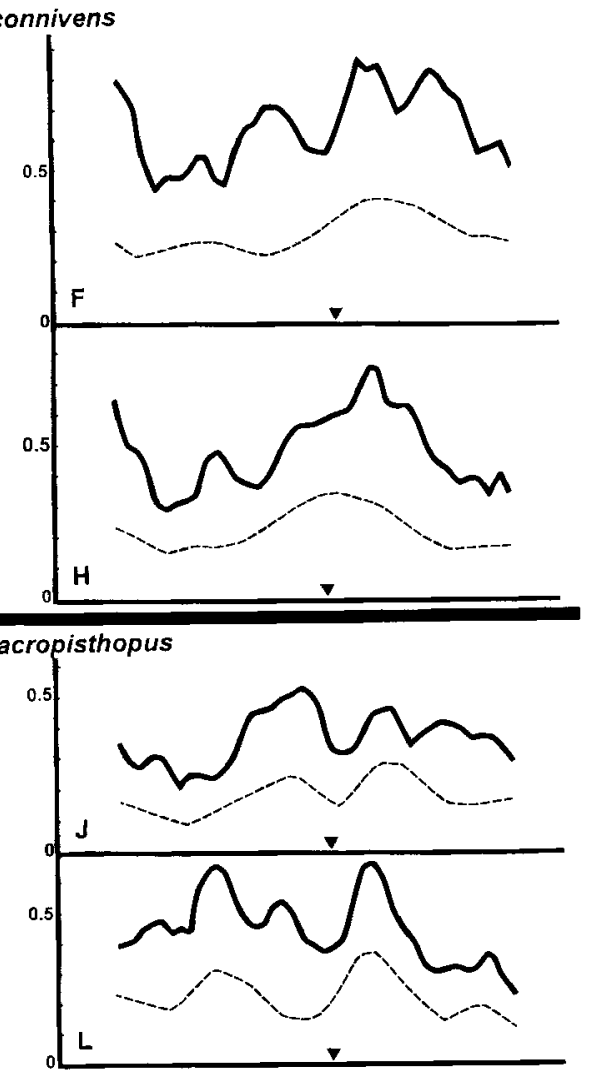

Points Along Body (50)

were used in graphic analysis; same individuals were observed on both smooth $(A, C, E, I, K)$ and rough surfaces (B,D,F,G,I,K) surfaces. A-D: $L$. lineopunctulata $(\mathbf{N}=2$ ). E-H: $L$. connivens $(\mathbf{N}=2)$. I-L: $L$. macropisthopus $(\mathbf{N}=2)$. 
Upon being placed into 2-cm channels of smooth Plexiglas, Lerista lineopunctulata starts progression by swinging the head against one wall, using the opposite wall as a resistance site against which to push with a bend of the trunk. Next, the trunk is pulled up into a tight curve and then second and third curves form posterior to the first. The head bends further, and the more posterior curves slide forward along the wall so that the zones of contact with the Plexiglas move closer to the snout (this gives the impression that the curves progress anteriorly, opposite to their logical posterior progression if the animal is attempting to move forward). The initial bend of the head may be either to the left or right; there is no regular alternation and the head may be pressed against the same wall several times in succession. Finally, with the posterior half of the trunk and the tail base and/or the hindlimbs pressed against the wall and/or the floor, the lizard relaxes starting with the anterior end. This relaxation straightens the muscular trunk, extending it anteriorly from the fixed pelvic zone and shifting the center of gravity along the channel.

In 2-cm channels with sandpaper walls, Lerista lineopunctulata progresses at least as well as in smooth channels. Contact with the wall induces drag but also increases static friction for concertina curves pushing laterally against the wall. In $2-\mathrm{cm}$ channels with sandpaper bottom, the lizards use both the friction of the ventral surface against the rough floor and the pressure of the body curves against the walls as in the smooth channels; they thus move quite well. The feet can be seen to flail; whenever they hook into the rough substrate, they aid progression.

Lerista lineopunctulata wedges sideways in the smooth 1-cm channels. It forms four curves along the trunk, but only a single half-curve along the tail. Thus the tail does not reverse curvature but remains mostly straight, in essence being dragged. The amplitude of the curves in the trunk is more than twice the amplitude of those of the tail. Progression is intermittent, $1-2 \mathrm{~cm}$ at a time at about one cycle per second (cps), apparently driven by forces applied where bends exert lateral pushes against the walls.

Lerista connivens has much more difficulty in passing along smooth channels. In $1-\mathrm{cm}$ channels, the trunk forms two or three curves, whereas the tail shows minimal curvature, bending only at the base and remain- ing straight to the tip. Progression is limited to lurches of $1-2 \mathrm{~cm}$ at less than $0.5 \mathrm{cps}$. In 2 -cm smooth channels, the lizards rapidly wave their feet. The head is rarely wedged toward the opposite side, and the trunk forms only a single $S$ curve that extends onto the base of the tail. This curve does not pass anteriorly. Only irregularly is the tail dragged anteriorly.

In the 2-cm channels with sandpaper walls, Lerista connivens again has difficulty progressing. Its feet slide as it attempts to walk and lateral friction keeps the body from sliding forward whenever it touches the walls. Much of the limited progression occurs whenever the feet incidentally contact the corner between the vertical and horizontal surfaces and the limb propels the trunk for a single cycle, although some progression is achieved by incidental concertina movements whenever bends of the body press against the walls. On the sandpaper bottom, this species advances with every step. Sometimes, the animals touch one wall with both the head and the cloacal region. The animals move most rapidly whenever they can keep the trunk straight and stride along the center of the channel.

Lerista macropisthopus has even greater difficulty in smooth channels. A single S curve forms on the body, but the tail remains straight. The body is not used to wedge, although the legs are moving. The tail almost wedges more than the body. The hind legs cycle, but lack traction and just swing back and forth. Only brief, irregular progression occurs. In the 1-cm smooth channel, the animals wedge themselves with their head and pull up the trunk slightly although their legs interfere with progression. About three curves form in the trunk. The tail is kept quite straight. In spite of much irregular struggle there is little propulsion.

Lerista macropisthopus attempts to walk down the 2-cm channel with sandpaper sides, the trunk passing full $\mathrm{S}$ curves. The tail shows a single, half curve. The legs move, but do not generate propulsion as they lack frictional contact. As the body touches the walls, it drags. One can see that the curves of the body and those of the tail form independently and are neither synchronized, nor of equivalent amplitude; rarely do the waves move from body onto tail. The head does not attempt to wedge.

In the 2-cm channel with the sandpaper bottom, Lerista macropisthopus walks effec- 
tively straight down the path and does not use the walls at all. The curves formed by the tail are mostly established by the deflection of the postcaudal region in synchrony with the rotation of the pelvic zone. Otherwise the tail is dragged.

The rates of progress among the three species in $2-\mathrm{cm}$ channels show notable differences depending on the character of the surfaces on the bottom and the sides of the channels (Table 3). Note that because the Lerista lineopunctulata used are longer than the other two species (which have approximately the same snout-vent lengths) its velocities could be up to $135 \%$ higher than would be expected if all three species were the same length. Even so, the comparisons stand.

Lerista connivens, and especially L. macropisthopus, walk relatively easily down $2-\mathrm{cm}$ channels with rough bottoms. In this situation, $L$. lineopunctulata progresses less rapidly; it uses a lateral concertina pattern, aided by occasional use of the hindlimbs if they catch onto the rough surface. In $2-\mathrm{cm}$ channels with rough sides, the outcomes are reversed; $L$. connivens progresses very slowly and L. macropisthopus hardly at all. Both depend on catching their hindlimbs on the rough wall near the base, although $L$. connivens has some ability to wedge its body against the wall and push laterally. $L$. lineopunctulata progress comparatively well, even in the smooth channels using their body curves to wedge laterally as they push themselves along by use of static friction against walls and bottom.

\section{DISCUSSION \\ Overview}

The three species of the skink genus Lerista analyzed here afford the opportunity of describing and evaluating locomotor differences in a single genus of terrestrial lizards displaying minor differences in elongation and limb reduction. These three species of Lerista display locomotory patterns intermediate between those of legged locomotion and fully legless, lateral undulation (the latter being a derived condition in which curvature of the body adjusts to local points of contact with the surface). The lizards were forced to move over several substrates that impose different locomotor tasks, letting one evaluate their distinct motor capacities. The approach combines direct observation with computer digitization, from video images, of the changing body curvatures. Analysis is possible as our program extracts several kinds of descriptors from the digitized data of the movements performed (such as the range of excursion and local curvature at points along the body). For curvatures the program can list mean and maxima observed during a sequence. The mean values permit characterization of movements, but the local maxima of curvature express the performance capacity of the specific portion of the body in the particular physical situation. Also, the extent to which the local excursion exceeds that of the center of gravity indicates the zones at which propulsion is centered.

The initial question is: What types of locomotion do these species use? Do the three species move equivalently or do they show differences as they move over smoothly finished and rough surfaces, among nails providing potential lateral resistance sites at different spacings, and through channels of different widths and with different frictional resistances on their floors and walls? After determining the locomotor patterns displayed, they can then be compared with those of previously analyzed species. The next question is: Are these three species capable of either true lateral undulation or of an advanced form of tunnel concertina in which lateral contact sites move gradually along the trunk as the animal progresses (Gans, ' 85 , '86)? The ecological and further comparative implications of the observations are reserved for another study.

This report represents the continuation and amplification of a series of observations made 15 years ago in Australia (Gans and Greer, '82; Gans, '85). Whereas, each of the locomotor patterns described here was observed then, it proved difficult to analyze them because the use of costly film rather

TABLE 3. Velocities of the three species of Lerista attained in 2-cm-wide Plexiglas channels ${ }^{1}$

\begin{tabular}{lccc}
\hline Substrate & L. lineopunctulata & L. connivens & L. macropisthopus \\
\hline Sandpaper bottom & $1.7-2.0(5)$ & $4.3-7.5(2)$ & $5.0-10.0(2)$ \\
Sandpaper sides & $1.4-1.7(4)$ & $0.6(1)$ & $0.14(1)$ \\
All smooth & $1.4(1)$ & $0.5(1)$ & No progress \\
\hline
\end{tabular}

${ }^{1}$ Numbers in parentheses are sample sizes. Velocities are in cps at $25^{\circ} \mathrm{C}$, measured for continuous travel over $10 \mathrm{~cm}$. 
than video had restricted filming to short sequences. The present data will permit reevaluation of some of the original films and indicate which of the earlier sampled species need to be analyzed further.

\section{Overall locomotor patterns and morphologies}

The locomotor patterns and body morphology of the three species of Lerista are generally similar but show some notable interspecific differences. All three are relatively large for the genus and show moderate ( $L$. macropisthopus) to relatively extreme ( $L . \quad l i$ neopunctulata) limb reduction associated with their fossorial habits. All three species show generally similar capabilities in curvature of the body with a few notable distinctions. All slide on their ventral surfaces with minimal lift during propulsion. All undulate their body to a greater or lesser extent during locomotion, whereas none of them appears capable of true lateral undulation. All three sandswim readily as soon as the heads are pushed far enough into the sand by body or hindlimbs to deploy a body curve; although $L$. macropisthopus, the species most often found on soils unsuitable for swimming, appears willing to remain on the surface whereas the other two species usually dive immediately.

Animals resting on smooth flat surfaces start locomotion by a concertina sequence using the static friction of the feet and of a fixed portion of the trunk. They generally use the moving inertia built up in the anterior portion to accelerate the posterior body. Initial acceleration tends to be more rapid on a high friction surface. Propulsion changes after all of the animal is in motion; velocity of the center of gravity is then maintained, and the momentum is used to overcome sliding friction. Consequently, fatiguing animals shift to an intermittent movement, instead of moving at a slower velocity. These trunk movements and locomotor patterns are roughly equivalent to those observed in $\mathrm{An}$ guis fragilis and in Ophisaurus apodus (Gans and Gasc, '90; Gasc and Gans, '90).

Lerista lineopunctulata locomotes primarily with its body. Members of this species are long, have more presacral vertebrae than the other two species and are relatively slender. They are especially slender near the pelvis, as one would expect given the degree of hindlimb reduction. L. lineopunctulata employs slide pushing on flat surfaces and during entry into sand. Indeed, individuals com- monly stand on surfaces with the head inclined downward. They seldom use their hindlimbs, which are reduced to (usually) one digit and three phalanges and a little over half the length of those of the other two species. Lateral displacement during locomotion is relatively wide, as the lizards deploy their body flexibility in force generating curves along the body and onto the long tail. L. lineopunctulata can travel even down the narrowest channels; for this it curves locally, extending a simple variant of lateral concertina forces against the walls.

Lerista connivens is relatively wide with a short body and tail (having the least number of both pre- and postsacral vertebrae of the three species). It has two-toed hindlimbs (eight phalanges), which are almost twice the length of those of L. lineopunctulata. L. connivens locomotes with a combination of walking, using the hind limbs (which are considerably longer than those of $L$. lineopunctulata) and slide pushing. In locomotion, the relatively stiff, short trunk displaces only slightly laterally whereas propulsion is effected by the hindlimbs or the swinging tail. The hindlimbs also drive entry into loose sands, and progression in channels occurs only whenever the feet of the lizards can achieve purchase; they appear unable to deploy body curves against channel walls for effective locomotion.

Lerista macropisthopus is similar to L. lineopunctulata in body proportion except that it has fewer presacral and more postsacral vertebrae, substantially larger hindlimbs (almost twice as long and with three toes, each having 10 phalanges) and a wider body near the pelvic girdle. It locomotes primarily by walking or limbed concertina. In spite of apparent body flexibility when handled, it does not use it to deploy curves. It does not use slide pushing and cannot progress in channels, except by use of the limbs. Neither the bodies nor the tails show wide displacement during locomotion and clear curvature minima occur at the level of the pelvis. $L$. macropisthopus enters loose sand by pushing into it with the hind limbs until the head and neck obtain a purchase, after which it sand swims.

\section{Mechanical principles \\ Friction, foot placement, and velocity}

The relative use of the several mechanical movement patterns differs with the species and with the frictional properties of the substrate. For a sliding lizard, this involves the 
conflict that an increased coefficient of friction facilitates force transmission by the ventral surfaces of their trunk and feet. However, a greater coefficient of friction also increases drag that must be overcome by more propulsive force. Hence, the locomotor performance of these lizards is highly dependent on the frictional characteristics of the substrate they are traversing.

The frictional problems explain the use of limbs and particularly of claws and the "searching" or repeated "cycling" movements of the limbs whenever no contact is made during a single pass over a flat substrate. 'Two of the three species achieve faster travel on flat sandpaper than on smoother surfaces, either by walking (for $L$. macropisthopus) or by slide pushing (for Lerista lineopunctulata). The improvement of performance by $L$. macropisthopus and $L$. connivens in sandpaper-floored channels is due to their use of the roughened substrate in toe placement. Also, the toes often contact and hook into roughened irregularities along the edges of the smooth-bottomed channels.

The importance of friction also explains the rate of locomotion, particularly in the traverse of flat surfaces and in those in which there are only a few nails, or nails at a spacing wide relative to the length of the lizards. In slow travel, the animals can search out localized ventral or lateral resistance sites and apply limited forces once such sites have been identified. With increases in the velocity, and likely the magnitude of the forces that must be transmitted, the potential for contact failure increases; observations of such slippage are associated with temporary irregularity of the velocity and acceleration curves of the lizards. The likelihood of contact slippage is then compensated for by utilization of momentum.

Maintenance of momentum implies more rapid traverse, sufficient so that temporary interruption of force application will lead only to slowing and never to a complete stop (with increased coefficient of friction). It also accounts for the cycling phenomenon seen upon contact failure in the limb movements. It further explains the sweeping high-amplitude curves seen whenever specimens traverse fields of nails in very open spacing. The posteriorly passing curves into which the trunk forms will generate propulsive forces only as long as they contact resistance sites; in the interim, the lizards continue to travel until the ventral sliding friction has over- come their kinetic energy. There then are two motor regimes: a slow one in which force application avoids slippage and interruption of contact sites, and a fast one in which the animal moves fast enough to assure an adequate number of encounters with contact sites per unit time. This generates a bimodal velocity distribution.

\section{Role of the tail}

In these Lerista, Anguis (Gasc and Gans, '90) and Anniella (Gans et al., '92), unlike the situation in Ophisaurus (Gans and Gasc, '90), the pattern of caudal curvature differs between trunk and tail and the waves are modified as they pass onto the tail. Nevertheless, the cloacal zone appears as a consistent site of discontinuity in displacement or curvature only in L. macropisthopus; it thus differs from the curvature patterns seen in $\mathrm{An}$ guis (Gasc and Gans, '90). In most cases, the tail provides limited propulsive support; the curvature is established semipassively by the alternating rotation of the pelvic girdle associated with placement of the feet. The coincidental effect of foot action represents the basis of the occasional pelvic discontinuities in displacement or curvature graphs.

Whereas slowly walking lizards commonly show only the passive caudal curves, one sometimes sees a caudal jerk, particularly during travel of Lerista lineopunctulata in narrow channels. In this the tail is rapidly recurved so that it sweeps through a lateral to a more anteriorly facing position. This obviously shifts the lizard's center of gravity anteriorly. Such jerking movement is generally part of a limbed (and caudal) concertina movement. The frictional force due to the mass of the recurved tail provides a new fixation site from which the trunk may be straightened. Also, anterior movement of the pelvic zone requires less force if only the trunk and pelvic zone, but not the caudal mass, need to be shifted.

The tail obviously participates in slide pushing, a rapid (energetic, but not fast) propulsive movement. Caudal propulsive bending can also be noted in traverse of nail arrays; as shown below, its usage and effectiveness vary with the nail spacing. The behavior of the individual Lerista macropisthopus with a completely regenerated but stiff tail suggests that the degree of regeneration, rather than its occurrence needs to be evaluated in considering the selective advantages and disadvantages of the phenomenon. 


\section{Tunnel concertina}

Only Lerista lineopunctulata traverses tunnels using concertina, and it uses a variant in which the head is initially fixed, attempting to drive laterally out of the tunnel wall. The back then swings against the opposite wall and an anterior curve set forms and fixes the lizard here. Relaxation is irregular, as is progression. Whereas bending in wide channels requires high curvatures, the curvature demands for narrow channels are much less than observed in other movements. The other species do not use tunnel concertina, even in such sites.

As noted earlier, the vertebral numbers and mean numbers of presacral vertebrae differ only slightly among the three species. The peaks of maximal curvature (Fig. 4) are slightly greater for $L$. lineopunctulata (46-48 presacral vertebrae; 0.42 vertebrae per unit of snout-vent length) than for $L$. connivens (41-43 presacral vertebrae; 0.53 vertebrae per unit of adult snout-vent length) and $L$. macropisthopus (43-46 presacral vertebrae; 0.56 vertebrae per unit of snout-vent length). As our measure of curvature is inversely proportional to the absolute length of the specimen, the above values suggest that $L$. lineopunctulata produces the tightest bends. Whereas local flexibility may be correlated with the vertebral count and length, the relationship seems to be parallel rather than causal. However, it is unlikely that the limitation in the usage of tunnel concertina locomotion results from a restricted capacity to form many tight curves rather than from a different pattern of sensorimotor coordination (Gans, '85).

\section{Passage of nail arrays}

Nail arrays model irregular natural environments in which the reduced-limb lizards have been observed to extend their horizontal propulsive forces against objects vertically displaced from the surfaces on which they rest. The spacing differs in being regular in both directions, and the records show that the animals must use different propulsive patterns as they shift from widely to tightly spaced arrays.

On smooth open surfaces, the undulating trunk of a moving lizard may form regular undulant curves that sweep posteriorly. The sweeping bends may contact individual nails. If the movement vector of the center of gravity falls on the line between the center of gravity and the nail, the force generated will act to accelerate the lizard on its original path. If the lines lie at an angle, the path will be deflected. Among other variables, the deflection will depend on the degree of tonic stiffness of the animal and on the extent to which its traveling curves will be affected by the force application.

As the density of nail spacing increases, the probability of multiple simultaneous contacts increases. The deformation of the sweeping curves is then limited, as is the shift in the path of the center of gravity. The animal is seen to undulate among the nails, as if it were using advanced lateral undulation; however, the curves seem to retain a standard shape and show minimal deformation in response to the sites of local force application. As the spacing decreases further, the path becomes constrained by nail contact. For instance, entry of the head into the gap between two rows of nails lets it be pushed down the aisle; the propulsive force involves the formation of a simple bend at the entrance to the channel, that shifts posteriorly as the animal slides through it. Transmission of forces along the trunk then involves intrinsic tonic stiffness. Observations show that the portion of the trunk that can be thus extended from one contact site depends on the resistance, i.e., the sliding friction with the substratum. Whenever the required force exceeds this frictional limit, the lizard hooks around a new site and starts a more anterior propulsive bend.

The capacity to form a single propulsive bend that acts against a fixed site is seen in all these species. It has also been noted in the lizards previously analyzed. The bend would appear to require minimal control, as the deformation of the animal is strictly constrained by the substratum. However, the capacity for such bend formation may provide the basis for the shift to derived lateral undulation. The behavior of lizards encountering only a single nail indicates the potential for the transition.

Whenever a resting animal can bend a portion of its trunk around a nail, it can pull against this by forming a U curve. The camfollower principle (Gasc et al., '89; Gans, '94; Gans and Burr, '94) indicates that the contact zone of nail and curved surface will slide away from the zone of maximum curvature. Hence, the lizard can pull itself anteriorly by 
forming a sharper curve close to the neck than on the other side of the nail contact.

In this case a general shift of curvature along the trunk generates the propulsion. This event does not need to be matched closely to a particular site. However, close matching to a specific site (which does not occur in these Lerista) permits undulating animals to utilize multiple peg-like or nail-like irregularities and to progress through very irregular arrays of resistance sites. The local deformation at each site proceeds on the cam-follower principle and allows the animal to determine the direction of the local vector. Whereas the body undergoes very minor local deformation at the site, the portions of the animal away from the site move along a single track as do the cars of a railroad train. This is the advanced lateral undulation; it apparently does not appear in Lerista (nor does it appear in Anguis, Ophisaurus, and Anniella ${ }^{1}$ ).

\section{SUMMARY}

Lerista lineopunctulata and $L$. connivens are most probably very closely related to each other, whereas L. macropisthopus is distantly related to them. Thus the limb loss pattern among the three species is not a phylogenetic sequence. L. macropisthopus represents a condition ancestral to that seen in the other two species; it shows most dependence on the limbs for locomotion and least ability to bring the body wall under control for such locomotory challenges as tunnel concertina. L. lineopunctulata represents a commitment to primarily legless locomotion and, relative to its close relative, $L$. connivens, appears to make greater use of its body wall during locomotion on smooth surfaces. It is far more effective in tunnel concertina locomotion than either of the other two species. This may be observed in channels with smooth bottoms and either smooth or rough walls; in these channels, the other two species cannot use the limbs effectively. Although all three species of Lerista are capable of sand-swimming, it is notable that $L$. lineopunctulata, the species with the least commitment to limbed locomotion, is associated with the deepest sands in its habitat,

\footnotetext{
1Some earlier studies (Gans and Gasc, '90; Gasc and Gans, '90; Gans et al., '92) contain an embarrassing error. It was noted correctly that the animals do not use advanced lateral undulation, rather than simple undulation. Regrettably, several graphs were labeled with the term "lateral undulation," which was inappropriate and misleading.
}

while L. macropisthopus, a strong walker, often occurs in habitats in which no open sandy areas are available. Differences in relative locomotory capabilities may play a role in the subtle separations of macro- and microhabitat among them in their native habitats (Kendrick, '91). The analysis shows that the minor morphological differences are associated with major functional ones.

\section{ACKNOWLEDGMENTS}

We thank Dr. F.H. Pough for loan of the living specimens on which these observations were made and access to an unpublished manuscript, the staff of the Herpetology group at the Museum of Western Australia (Perth) for loan of dissection materials and much help during field work (to M.F.), and Brad Moon for comments on the manuscript. The Leo Leeser Foundation supported the studies of C.G. with funds for travel, equipment and supplies. This work was reported on at the 2nd International Congress of Herpetology (Fusari et al., '93).

\section{LITERATURE CITED}

Fusari, M.H., C. Gans, and F.H. Pough (1993) Surface locomotion of three fossorial species of Lerista (Scincidae) from Western Australia. In Second World Congress of Herpetology, Adelaide, South Australia, December 29, 1993, p. 93 (abstr.).

Gans, C. (1975) Tetrapod limblessness: evolution and functional correlation. Am. Zool., 15:455-467.

Gans, C. (1985) Motor coordination factors in the transition from tetrapody to limblessness in lower vertebrates. In B.M.H. Bush, and F. Clarac (eds): Coordination of Motor Behaviour. Soc. Exp. Biol. Sem. Ser. 24. Cambridge: Cambridge University Press, pp. 183-200.

Gans, C. (1986) Locomotion of limbless vertebrates: pattern and evolution. Herpetologica 42:31-46.

Gans, C. (1994) Approaches to the evolution of limbless locomotion. Cuad. Herpetol. 8:12-17.

Gans, C., and A.H.J. Burr (1994) Unique locomotory mechanism of Mermis nigrescens, a large nematode that crawls over soil and climbs through vegetation. J. Morphol. 222:133-148.

Gans, C., and J.-P. Gasc (1990) Tests on the locomotion of the elongate and limbless reptile Ophisaurus apodus (Sauria: Anguidae). J. Zool. (Lond.) 220:517-536.

Gans, C., and A. Greer (1982) Locomotor patterns in some crepuscular skinks of Australia. In Prog. Abs. Silver Anniv. Meeting, Society for the Study of Amphibians and Reptiles, Raleigh, N.C., Aug. 1-6, 1994, p. 72.

Gans, C., W.K. Morgan, and E.S. Allen (1992) Surface locomotion of the elongate and limbless reptile $A n$ niella pulchra. Herpetologica. 48:242-258.

Gasc, J.-P. (1977a) Mécanismes de la rudimentation des organes chez les embryons de vertébrés. Coll. Int. C.N.R.S. Paris 266:341-352.

Gase, J.-P. (1977b) Correlations anatomiques dans le squelette et la musculature des reptiles serpentiformes. Coll. Int. C.N.R.S. Paris 266:353-364. 
Gase, J.-P. (1981) Axial musculature. In C. Gans and T.S. Parsons (eds): Biology of the Reptilia. Vol. II. London: Academic Press, pp 355-435.

Gasc, J.P., and C. Gans (1990) Tests on the locomotion of the elongate and limbless reptile Anguis fragilis. Copeia 1990:1055-1067.

Gasc, J.-P., D. Cattaert, C. Chasserat, and F. Clarac (1989) Propulsive action of a snake pushing against a single site: its combined analysis. J. Morphol. 201:315329 .

Greer, A.E. (1987) Limb reduction in the lizard genus Lerista. 1. Variation in the number of phalanges and presacral vertebrae. J. Herpetol. 21:267:276.

Greer, A.E. (1990) Limb reduction in the lizard genus Lerista. 2. Variation in the bone complements of the front and rear limbs and the number of postsacral vertebrae. J. Herpetol. 24:142:150.

Greer, A.E. (1991a) The Biology and Evolution of Australian Lizards. Chipping Norton: Surrey Beatty \& Sons.

Greer, A.E. (1991b) Limb reduction in squamates: identification of the lineages and discussions of the trends. $J$. Herpetol. 25:166-173.

Kendrick, P.G. (1991) The Phylogenetics and Comparative Ecology of Lerista Bell, 1833; Patterns of Evolution in a Genus of Sand-Swimming Skinks. Disserta- tion. Department of Zoology, University of Western Australia.

Mushinski, H., and C. Gans (1992) The role of the tail in tunnel passage by Neoseps reynoldsi. Amphibia Reptilia 13:393-404.

Pough, F.H. (1991) Recommendations for the care of amphibians and reptiles in academic institutions. ILAR News 33:S1-S21.

Raynaud, A. (1972) Morphogenèse des membres rudimentaires chez les reptiles: un problème d'embryologie et d'évolution. Bull. Soc. Zool. Fr. 97:469-485.

Raynaud, A. (1974) Données embryologiques sur la rudimentation des membres chez les reptiles. Bull. Soc. Hist. Nat. Toulouse 110:26-40.

Raynaud, A. (1976) Les différentes modalités de la rudimentation des membres chez les embryons de reptiles serpentiformes. Coll. Int. C.N.R.S. 266:201-217.

Raynaud, A. (1985) Development of limbs and embryonic limb reduction. In C. Gans and F. Billett (eds): Biology of the Reptilia. Development. B. Vol. 15. New York: John Wiley \& Sons, pp. 59-148.

Storr, G.M., L.A. Smith, and R.E. Johnstone (1981) Lizards of Western Australia. I. Skinks. Perthi University of Western Australia Press with West Australian Museum. 